\title{
The Influence of Moraic Structure on L2 English Syllable-Final Consonants
}

\author{
Noriyasu Harada Li and Alan Juffs \\ University of Pittsburgh
}

\begin{abstract}
It is widely acknowledged that native speakers (L1) of Japanese face a number of challenges when learning English, such as in producing syllable-final consonant segments, and differentiating between L1 and L2 syllable structures. The inability to produce such segments potentially lies in the characteristic of the Japanese language that is often called 'mora-timed.' This study examines how L1 Japanese errors with syllables are related to the mapping of mora-sized units onto English rather than syllable structure per se. The evidence for this is that L1 Japanese speakers can produce some but not all L2 English syllable-final consonant segments, and this production is not predictable by segment type. Data from 20 Japanese participants in a free production task were analyzed in comparison to 20 Chinese and 20 Korean participants, who also have syllable coda challenges. Acoustic analysis of these recordings revealed that the English production of Japanese speakers shows an effect of moraic structure in that codas are preserved, whereas Chinese and Korean speakers delete segments under the influence of their respective syllable structure constraints. Statistical analysis, using an univariate ANOVA confirmed that the L1 effect is significant for deletion $(F(2,57)=10.942, p \leq .0001)$ and preservation $(F(2,57)=12.810, p \leq .0001)$. Moreover, in undeleted codas a repeated measures ANOVA confirms a reliable L1 by repair interaction between laryngeal modification (Japanese) and epenthesis (Chinese and Korean) $(F(2,57)=10.942, p<.05)$. These results suggest crosslinguistic influence at a phonological level higher than the syllable, signifying that moraic structure constrains L1 Japanese production of L2 syllable-final consonants. This research permits a more comprehensive view of L2 production, probing why and how differences in syllable structures affect overall L2 English production. These second language data also provide support for the existence of the mora in L1 Japanese, which has been a controversial topic in Japanese phonology.

Keywords: Mora, syllable structure, syllable-final consonants, L2 English
\end{abstract}

\section{Introduction}

A consensus exists that the L1 plays a major role in the inability to achieve native-like competency in L2 production, but the question remains as to what the exact role of the L1 is. Extensive research has been conducted on L2 phonological acquisition, focusing on the production of individual L2 segments (e.g., Best, 1995; Brown, 2000; Flege, 1995; Aoyama, Flege, Guion, Akahane-Yamada \& Yamada, 2004), and also on L2 consonant codas (Hansen, 2004; Nogita, 2011). L1 Japanese-speaking learners of English have often been observed to produce words with consonant codas with either epenthesis of the hard word-final consonant, a devoiced consonant that should be voiced, deletion, or increased aspiration. In a word with two or more syllables, L1 Japanese speakers tend to produce each syllable evenly instead of distinguishing between the primary stress and unstressed syllables. These tendencies are also prevalent among L1 Chinese and L1 Korean learners, who face similar consonant coda constraints from their L1, and do not have the primaryunstressed syllable distinctions. However, differences arise in the types of errors L2 learners tend to make and also in the repair strategies they utilize when inaccuracies occur.

\footnotetext{
${ }^{*}$ We are sincerely grateful and acknowledge the support of the Department of Linguistics and English Language Institute at the University of Pittsburgh, and the Pittsburgh Science of Learning Center. The authors are grateful to acknowledge the members of the Department of Linguistics for their helpful comments and suggestions throughout the various stages of this research project. This research was supported in part by a grant from the Pittsburgh Science of Learning Center to Alan Juffs. The Pittsburgh Science of Learning Center is funded by the United States National Science Foundation award number SBE-0836012. Previously, it was NSF award number SBE-0354420 and a Foreign Language Area Studies Fellowship to Noriyasu Harada Li.
}

(C) 2015 Noriyasu Harada Li and Alan Juffs

Proceedings of AMP 2014

Completed March 1, 2015. 
Extensive research has examined how L2 learners overcome their L1 constraints in L2 production; however, the focus has been on the linguistic constraints learners must overcome in order to produce the individual segment they are trying to achieve. Yet, what is important for L2 learners is not just the ability to produce individual segments, but the ability to combine these segments in a sequence that is required by the target language (Young-Scholten \& Archibald, 2000). Furthermore, once the target segments are in sequence, syllable structures and timing also need to be carefully examined. It has been widely recognized that L1 syllable structure does influence L2 speech, and in the process it creates a suprasegmental constraint on segmental organization for L2 learners. This paper examines how the moraic structure of Japanese influences L2 production overall and specifically how the mora affects English L2 syllable-final consonants. We compare this influence to the production of Chinese and Korean-speaking learners of English. Because the ability to overcome linguistic constraints and produce individual L2 English sounds is a necessary component of L2 production, this work will provide a better understanding of how higher level constraints of the L1 play a role in L1-L2 crosslinguistic influence.

\section{Phonological acquisition}

Early frameworks, such as the contrastive analysis framework (Lado, 1957), addressed how the L1 influenced the acquisition of an L2 segment and suggested learners would have more difficulty learning an L2 sound if it had no equivalent sound in their first language. The perceptual assimilation model (PAM) (Best, 1995) and the speech learning model (SLM) (Flege, 1995) addressed similar phonological constraints. The PAM claimed the role of the speaker's L1 phonological system plays a role in the perception of nonnative sounds, and non-native sounds are assimilated to a listener's L1 phonological categories on the basis of articulatory similarity. The SLM argued that L2 segments are acquired based on the degree of difference of two sounds - if a native and non-native sound are more different from each other, the L2 learner will have a greater chance of acquiring a non-native sound compared to two sounds that are similar to each other. However, neither the PAM nor SLM articulate the underlying mechanism of how learners map L2 sounds onto target language categories.

Nonetheless, the existing research on phonological acquisition, including the PAM and SLM, has led to the consensus in phonological theories of SLA that the L1 plays a major role in the inability to achieve nativelike production. However, the exact role in phonological subdomains of the L2, which properties are acquirable, and which other properties and structures remain more difficult to, or impossible to acquire, all remain to be clarified.

In terms of L1 Japanese acquisition of L2 English, the research is rich in both the production of English consonants (e.g. Tajima, Erickson \& Nagao, 2003), as well as perception (e.g. Dupoux, Kakehi, Hirose, Pallier \& Mehler, 1999). Research on consonant segments are of particular interest in L2 English acquisition, because Japanese is a language that restricts syllable-final consonants, creating a phonological constraint. However, much of the research in L2 phonological acquisition, as with other studies in the field, have focused on the ability of producing individual L2 segments, such as the English / $/$ / for L1 Japanese (Aoyama et al., 2004). Not as much research has focused on how the moraic structure of Japanese influences the production of L2 syllable-final consonants, particularly on the errors, such as epenthesis, that speakers make. Thus, it is necessary to examine the total production of an individual's speech by statistical and acoustic analysis, which should reveal how L1 syllable structures transfer to their L2 speech, providing a better understanding of how the role of the L1 influences the L2.

\section{The significance of the mora}

Before further examining L1 Japanese production of L2 English, it is first necessary to address the moraic structure of Japanese. Japanese is often categorized as a 'mora-timed' language (Cutler \& Otake, 1994; Kubozono, 2002; Murty, Otake \& Cutler; 2007; Shibatani, 1990; Tsujimura, 2007; Vance, 1987), in contrast to 'stress-timed' languages such as English, and 'syllable-timed' languages such as Chinese and Korean. One of the central issues in the description of Japanese phonology and moraic theory is the precise role that the mora plays in the language, and even whether Japanese is actually a mora-timed language at all. This section will briefly discuss the significance of the mora in Japanese (see Warner \& Arai, 2001, for a full review on experimental studies on the mora). 
First, the mora functions as a durational unit of length and rhythm, and is an important aspect in the writing system of kana. It is the dominant category that determines how speech aligns with rhythm and timing in Japanese. The following words exemplify features of the mora in Japanese. Aside from inherent factors that cause differences in duration, such as the mora $/ \mathrm{ki} /$ being shorter than the mora $/ \mathrm{ka} /$ as high vowels are inherently shorter than low vowels (Warner \& Arai, 2001), the following words in (1) are perceived by L1 Japanese to have the same number of morae (4 in each case), even though the words have different numbers of syllables (adapted from Kubozono, 2002):

(1) a. to-o-kyo-o 'Tokyo' too.kyoo
b. a-ma-zo-n 'Amazon' a.ma.zon

c. a-me-ri-ka 'America' a.me.ri.ka

As we can see in (1), 'Tokyo' has two syllables, 'Amazon' has three, and 'America' has four in Japanese, yet all words have four morae. This is based on four factors of how morae and syllables are on different levels in Japanese: (i) the mora nasal / $\mathrm{N} /$, as seen in (1b) takes one mora unit at the coda position, (ii) the geminate can occupy a unit of length (as will be shown shortly), (iii) the second half of long vowels, as seen in (1a), and (iv) the second half of diphthong sequences (Kubozono, 2002).

The prominence of the mora in Japanese can be found in poetry. Haiku, a form of Japanese poetry, is strictly prescriptive in its structure and the number of morae it contains (Otake, Hatano, Cutler \& Mehler, 1993; Cutler \& Otake, 1994; Kubozono, 2002). A haiku is constructed of three phrases, the first and third phrase having five morae, and the intermediate phrase having seven morae, creating a 5-7-5 moraic sequence. Consider the following two haiku ((2) adapted from Kubozono, 2002, (3) adapted from Otake et al., 1993):

(2) ya.se.ga.e.ru / ma.ke.ru.na.is.sa / ko.re.ni.a.ri 'Never give up, thin frog; Issa is here with you"

(3) si.n.si.n.to / u.me.ti.ri.ka.ka.ru / ni.wa.bi.ka.na

"In silence they fall, into the garden bonfire, petals of the plum"

In (2), the geminate consonant in 'issa' (the first [s] being the geminate consonant) occupies a moraic unit, and "forms a standard seven-mora phrase together with the preceding word makeruna" (Kubozono, 2002, p. 33). In (3), we see that although the first phrase only has three syllables ( $\sin$-sin-to), it consists of five morae, and this consistency in Japanese poetry cannot be met if the phonological form of haiku are defined by the syllable.

The mora also plays an important role in perception. Dupoux et al. (1999) found that Japanese speakers tend to perceive an "illusory" vowel sound in between consonant clusters, even when there was clearly no vowel between two consonants. In contrast, French speakers, a language that permits consonant clusters, did not perceive any vowel between consonant clusters. It is likely that the Japanese speakers perceive this illusory vowel because they rely on their native phonotactics, ${ }^{1}$ particularly the CV structure, which can be interpreted as mora-based (Kubozono, 1995), and as a cue when segmenting spoken words (Otake et al., 1993). Although there are other phonotactic structures in Japanese, the CV structure is statistically dominant, and the main driving force that creates mora-rhythm (Dauer, 1987).

As observed above, moraic structure plays a significant role in Japanese, and subsequently, there have been many experimental studies examining the function of the mora. Research has examined various aspects of the role of the mora, such as the duration of mora segments in negative correlations between the duration of adjacent consonants and vowels in the CV structure (Port, Al-Ani \& Maeda, 1980), and positive correlations between the word length and mora(e) (Bradlow, Port \& Tajima, 1995; Port, Dalby \& O'Dell, 1987). However, most of the experimental studies on the role of the mora, mainly focus on Japanese, and not as much on the relevance of the mora in L2 production. In addition to L1 Japanese tendencies to perceive an illusory vowel in consonant clusters, if perception and production are interlinked, we should see the predominant CV mora structure of Japanese transfer in L2 production as well. Based on these premises, the

\footnotetext{
${ }^{1}$ There are four basic types of singleton morae in Japanese phonotactics: V (vowel), CV (consonant + vowel), $\mathrm{CjV}$ (consonant + palatalized consonant + vowel), $\mathrm{N}$ (mora nasal), and a geminate, which is a mora obstruent. A consonant in Japanese may also have a diacritic, or have a glide between the $\mathrm{C}$ and $\mathrm{V}$, but in both cases the product is still considered a single mora (Tsujimura, 2007).
} 
current study focuses on whether error types in L2 English syllable-final consonants by L1 Japanese are influenced by the moraic structure, rather a constraint at the syllable or segment level.

\section{Syllable structures and the sonority cycle}

As previously mentioned, although Japanese is considered a mora-timed language, and Chinese and Korean are considered syllable-timed, all three languages have very similar syllable structures. The maximal syllable projection of Japanese is often considered to be /CVC/ or /CVV/ (Labrune, 2012); however, this can be extended to /CVN/ based on the evidence from the previous section, as well as /CVQ/, /CGVQ/ and $/ \mathrm{CGVN} /$ as permissible syllable structures in Japanese. The main restriction in Japanese syllable structures is that consonant clusters are restricted in Japanese. ${ }^{2}$ In Chinese, the maximal syllable projection is /CGVX/, where either a vowel, or $/ \mathrm{n} / / \mathrm{y} /$ or $/ \mathrm{t} /$ can occur in the final position. Similar to Japanese, consonants are not permitted in the syllable-final position, nor are consonant clusters. Korean, in contrast to Japanese and Chinese, allows consonants in the syllable-final position, and has a maximal syllable projection of /CGVC/ (Ahn, 1998). The /p/ /t/ /k/ /m/ /n/ / j/ and /1/ can all occur in the final position, but with restrictions. The stops are unreleased when they are in syllable-final position, and consonant clusters are restricted within the syllable. However, consonant clusters can occur across syllables, such as /hag.saeng/ (lit. 'student') or /il.bon/ (lit. 'Japan').

Aside from the existence of some consonant codas in Korean, the syllable structures of the three languages are relatively similar. However, differences arise in how speakers segment the syllable. Syllables are generally organized and segmented by speakers based on their respective L1 syllable structure and phonotactics, but also on a recurring cycle of maximal sonorant and obstruent peaks; i.e. the sonority cycle dictates how a speaker and listener produce and perceive the syllable. The organization of sonorant and obstruent peaks can be defined by four phonological features (Clements, 1990): Vowel (V), liquid (L), nasal $(\mathrm{N})$, and obstruent $(\mathrm{O})$, and characterized with plus-specifications (Table 1), creating a scale of sonority:

Table 1: Sonority scale of vowels, liquids, nasals, and obstruents (Clements, 1990)

\begin{tabular}{|l|c|c|c|c|}
\hline & $\mathrm{V}$ & $\mathrm{L}$ & $\mathrm{N}$ & $\mathrm{O}$ \\
\hline Vocoid & + & - & - & - \\
\hline Approximant & + & + & - & - \\
\hline Sonorant & + & + & + & - \\
\hline Scale & 3 & 2 & 1 & 0 \\
\hline
\end{tabular}

Based on this scale, vowels are maximally sonorant, followed in decreasing order in sonority by the liquid, nasal, and obstruents. This leads us to the following hierarchy of sonority (with the inclusion of the glide): V $>\mathrm{G}>\mathrm{L}>\mathrm{N}>\mathrm{O}$ (Broselow \& Finer, 1991; Hancin-Bhatt \& Bhatt, 1997). This hierarchy also correlates with how the vocal tract opens and closes when producing sounds. When the vocal tract is open, it releases the most sonorant sound, and when it is closed, it restricts the output of sonority. As it is physically impossible for speakers to sustain the opening of the vocal tract, it cycles between opening and closing, which correlates with a sonority cycle (Selkirk, 1984). The sonority cycle of how speakers segment syllables is illustrated in Figure 1 .

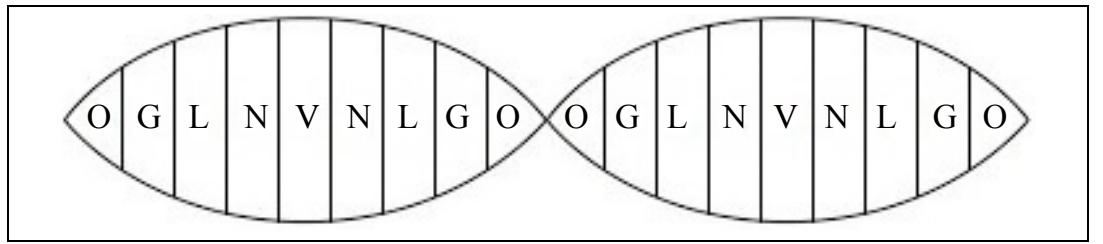

Figure 1: Universal model of segmenting syllables based on the sonority cycle

\footnotetext{
${ }^{2}$ In Japanese, speakers tend to devoice high vowels, such as /i/ and /w/, when they appear between two voiceless segments (Vance, 1987), and therefore are able to produce some voiceless consonants in sequence, such as dropping the [i] in /kita/ and producing it as $/ \mathrm{kta} /$.
} 
Segmenting syllables based on a cycle that alternates between maximally sonorant and obstruent sounds is generally universal among languages. In this cycle, the vowel occupies the maximally sonorant position, and any contrast in sonority created by an adjacent sounds, such as an obstruent, creates a CV contrast between maximally sonorant and obstruent segments. This establishes the perception of a syllable. The CV structure, which is the optimal syllable structure (Clements, 1990), is, as mentioned earlier, statistically the most dominant structure in Japanese, and is the case for Chinese and Korean as well.

The differences in how L1 Japanese, L1 Chinese, and L1 Koreans segment syllables can be analyzed through the sonority cycle and respective syllable structures. For example, nasals can occupy an entire unit of length and can stand alone within a syllable in Japanese, something that is not realized in Chinese. In Chinese, there is not a syllable contrast between [ki] and [kin], as both would be within one syllable boundary (Duanmu, 1990). In Korean, similar to Chinese, the /n/ also cannot stand independently, and must be within a syllable boundary. However, in Japanese, there is clearly a contrast between [ki] and [kin], because the $/ \mathrm{n} /$ occupies a mora, giving it functionality that does not exist in Chinese or Korean. This leads to the possibility that all three L1 groups may utilize not only different segmentation strategies, but may also use different repair strategies in consonant codas that are not part of their L1 phonological inventory. For example, in a word such as [food], the syllable-final [d] cannot stand in the coda position alone in any of the three languages. Thus, speakers who are unable to accurately produce the final voiced consonant will initiate a repair strategy in production. For L1 Japanese, when they cannot produce the final consonant, it is likely that they will preserve it to some degree instead of deleting the final consonant, because of the prevalence of the moraic structure in Japanese, which influences the mapping of mora-sized units into L2 English. By keeping the final [d], it is possible that an L1 Japanese would utilize a preservation strategy in repairing the final consonant to conform to Japanese phonotactic and structural rules. However, L1 Chinese and L1 Koreans may not be inclined to preserve the final [d], because the syllable has already been fulfilled as they map syllable-sized units into L2 English, which are larger than the mora-sized units. Adding an epenthesis to the final [d] would force the construction of a new syllable for L1 Chinese and L1 Koreans, which may not be necessary for L1 Japanese speakers. Based on these premises, we promote two different repair strategies one that preserves the coda consonant in some capacity, and one that employs complete deletion of the syllable-final consonant.

\section{L2 English syllable-final consonants}

Research on the production of L2 English syllable-final consonants by Japanese, Chinese and Korean speaking learners are extensive. Studies have shown that L1 Japanese speakers have a tendency to epenthesize consonant codas in production (Hancin-Bhatt \& Bhatt, 1997; Tajima et al., 2003), as well as inserting an epenthetic vowel between consonant clusters (Masuda \& Arai, 2010; Nogita, 2011; Tajima et al., 2003). As previously mentioned, epenthesis is likely to be driven by the dominant CV structure in Japanese, and this tendency of epenthesis has been found in perceptual studies as well (Dupoux et al., 1999). However, epenthesis as a repair strategy of syllable-final consonants is not Japanese-specific, as it has also been found in studies with L1 Mandarin speakers (Abrahamsson, 2003; Hansen, 2001), L1 Korean speakers (Kang, 2003 for production; Kabak \& Idsardi, 2007 for perception), and other Asian languages (Hansen, 2004 for L1 Vietnamese). Kang (2003) points out Koreans are likely to epenthesize a consonant if it is released in the original English form, and Hansen (2004) suggests linguistic environment and grammatical conditioning as the main factor for the inability to produce consonant codas. Studies have also reported that other repair strategies as the preferred method, such as devoicing (Chan, 2008 for L1 Cantonese; Eckman \& Iverson, 1994 for L1 Korean; Edge 1991 for L1 Japanese) and deletion (Wang, 1995, and Broselow, Chen \& Wang, 1998, for L1 Mandarin). Thus, the existing research shows some variability in the types of repair strategies used in $\mathrm{L} 2$ production.

Most of the previous studies on the production of syllable-final consonants have focused on how linguistic constraints influence production. In the case of L1 Japanese speakers, it appears that they are able to produce some syllable-final segments, but not all. Individual variability means that production is not predictable by one specific segment type. It does not seem that segmental constraints in codas are the only factor in their limitation, and other L1 constraints may also be influential factors. It is therefore critical to examine whether constraints at a higher prosodic level are influencing the inability to accurately produce syllable-final consonant segments. Clearly moraic structure plays a key role in Japanese phonology; therefore, 
studies on relevance of the mora in L2 transfer and L2 English production are necessary. Specifically, in a cross-linguistic analysis of how speakers of different languages with similar syllable structure repair English syllable-final consonants, we believe that L1 Japanese speakers may rely on characteristics of moraic structure in repairing L2 English syllable-final consonants, whereas Chinese and Korean speakers will utilize their respective L1 syllable structures in repairing consonants.

\section{Current Study}

This study therefore examines the production of obstruent syllable-final consonants by L1 Japanese, L1 Chinese, and L1 Korean learners of L2 English. Based on the previous research, the data should reveal the following error tendencies: L1 Japanese speakers may preserve final consonants, while L1 Chinese speakers may delete the most, and L1 Koreans may delete the final consonant more than other strategies since most syllable-final obstruents in English are released. In comparison to the production by L1 Chinese and L2 Koreans, we predict that L1 Japanese will employ repair strategies in errors with syllable-final consonants that are influenced by the moraic structure of Japanese. Subsequently, we predict that L1 Chinese and L1 Koreans will also utilize repair strategies of consonants defined by their L1 syllable structures as well. Furthermore, if different speakers employ the same repair strategies on the same word, such as epenthesizing a voiced stop consonant, we predict that the epenthesis by L1 Japanese speakers will be reflective of the mora structure of Japanese; i.e. the duration of the epenthesis should be relatively equal to the preceding vowel of the adjacent consonant. We do not believe this will be the case for L1 Chinese and L1 Korean speakers because of their respective syllable structures. The following three hypotheses sum up the goals that were set out for this study:

1) L1 Japanese will preserve the syllable-final consonant more than delete, L1 Chinese and L1 Koreans will delete the syllable-final consonant more than preserve. This is because the mora provides a timing unit that may exceed those for segments in a syllable as shown in (1).

2) Repair strategies by L1 Japanese speakers are influenced by the moraic structure of Japanese, due to the mapping of mora-sized units into English rather than the syllable structure per se.

3) L1 Chinese and L1 Korean repair strategies are influenced by their respective syllable structures.

\section{Method}

The present study analyzed audio recordings of 20 L1 Japanese, 20 L1 Chinese, and 20 L1 Korean speakers, and 10 males and 10 females in each L1. The data were made available by an intensive English program (IEP) at an American university, where all speakers in the study were students. All speakers are of similar intermediate level in terms of their speaking proficiency and their entrance exam scores to the IEP. We only examined similar levels of proficiency to reduce any variability in comparing a wider range of levels such as from an elementary to advanced level speaker. The intermediate level was also the most available level of proficiency at the IEP, as there were more students at the intermediate level compared to other levels. This made it possible to collect a sufficient and appropriate number of data and participants in our study. None of the speakers in the study had spent more than one year at the IEP or in the United States.

The data are taken from recorded speaking activities (RSAs) at the IEP. RSAs are spontaneous speaking tasks that are part of speaking classes at the IEP. Thus, the data collected were not from a task specifically designed to elicit words with codas, but were recordings that reflected unprompted and unscripted speech of a fairly natural kinds in terms of focus on meaning and thus elicit natural intonation and rhythm. In an RSA, a student records a monologue for a maximum of two minutes based on a given prompt. These prompts concerned familiar topics, such as "Is shopping for food the same in your country as in the US?" The topics were presented at the beginning of the task, and students had two minutes to think about the topic before recording their speech. During the in-class activity, once the student finished recording their speech, they had an opportunity to review their first speech and noted any mistakes they recognized, and record it a second time. However, only the first spontaneous recording of each RSA was used.

From this data-base, a total of 3,663 syllable-final consonants were selected from the speech data. In addition to obstruent segments, liquids in syllable-final positions were analyzed as well, as they are also not permitted in codas in Japanese and Chinese, but are in Korean (as long as they are unreleased). In all, L1 
Japanese speakers yielded 1,196 syllable-final consonants, 1,260 consonants by L1 Chinese, and 1,207 consonants by L1 Koreans. Acoustic analysis of all speech data, which were in .wav format, was performed using PRAAT (speech analyzing freeware). The data were analyzed by the following methods: (i) syllablefinal consonants were first coded for whether the speaker produced them accurately or inaccurately; (ii) if inaccurate, the syllables-final consonants were coded for whether the final segment was deleted or preserved in some degree; (iii) preserved syllable-final obstruents were coded by following alternations: 'epenthesis,' 'aspiration,' and 'devoicing.' If the participant completely mispronounced the syllable-final segment, it was categorized as 'other'; thus, no data points were excluded from the study. A univariate measures ANOVA was conducted for the results on whether speakers deleted or preserved the syllable-final consonant, and a repeated measures ANOVA was conducted for the results on all preserved consonant segments.

\section{Results}

We conducted a two-step analysis in examining the data. The first step examined whether there was a statistical difference between the preserved and deleted syllable-final consonants, and the second step examined whether there was a statistical difference within the preserved consonants. Table 2 shows the results of whether the Japanese, Chinese, and Korean speakers preserved or deleted the syllable-final consonant, and Table 3 shows the types of errors they made when syllable-final consonants were preserved (note that 'other' error types are included on the tables). Of the total number of consonants that were inaccurately produced, there was a substantial number of syllable-final consonants that were preserved over deleted by the L1 Japanese speakers (84\% of all errors were not deleted) in comparison to the L1 Chinese (54\% preserved) and L1 Korean (58\% preserved) speakers. The L1 Chinese speakers deleted syllable-final consonants 294 times (42\%), while L1 Koreans deleted 192 syllable-final consonants (35\%), and L1 Japanese speakers only deleted a total of 85 consonants (13\%).

Of the total number of syllable-final consonants that were preserved, both L1 Japanese and L1 Chinese speakers epenthesized the consonants 156 times ( $24 \%$ of the total errors by L 1 Japanese, $22 \%$ by L1 Chinese), and L1 Koreans epenthesized 102 times (18\%). Although all speakers devoiced many consonants, L1 Japanese did so more than the other two L1 speakers ( 272 times, $41 \%$ by L1 Japanese, 187 times, $26 \%$ by L1 Chinese, and 187 times, $24 \%$ by L1 Koreans). The most substantial difference between the groups was the number of consonants L1 Japanese speakers aspirated compared to the other two L1 speaker (132 times, $20 \%$ by L1 Japanese, 37 times, $5 \%$ by L1 Chinese, and 34 times, (6\%) by L1 Koreans). Overall, the data show that L1 Japanese prefer to devoice the syllable-final consonants the most, followed by epenthesis, aspiration, and then deletion. L1 Chinese speakers prefer to delete the final consonant the most, then devoice, epenthesize, and aspirate. L1 Koreans show a similar pattern to the L1 Chinese speakers.

Table 2: Total number preserved and deleted syllable-final consonants.

\begin{tabular}{|l|c|c|c|}
\hline \multicolumn{1}{|c|}{ L1 } & Preserved & Deleted & Total \\
\hline Japanese & $560(84 \%)$ & $85(13 \%)$ & $666 / 1196(56 \%)$ \\
\hline Chinese & $380(54 \%)$ & $294(42 \%)$ & $706 / 1260(56 \%)$ \\
\hline Korean & $323(58 \%)$ & $192(35 \%)$ & $553 / 1207(46 \%)$ \\
\hline
\end{tabular}

Table 3: Total number of errors from preserved syllable-final consonants.

\begin{tabular}{|l|c|c|c|c|}
\hline \multicolumn{1}{|c|}{ L1 } & Epenthesis & Aspiration & Devoicing & Total \\
\hline Japanese & $156(24 \%)$ & $132(20 \%)$ & $272(41 \%)$ & $666 / 1196(56 \%)$ \\
\hline Chinese & $156(22 \%)$ & $37(5 \%)$ & $187(26 \%)$ & $706 / 1260(56 \%)$ \\
\hline Korean & $102(18 \%)$ & $34(6 \%)$ & $187(34 \%)$ & $553 / 1207(46 \%)$ \\
\hline
\end{tabular}

The results from Table 2 (the total number of preserved syllable-final consonants) were submitted to a univariate ANOVA, to test for statistical significance of the L1. The L1 effect was significant $(F(2,57)=12.810, p \leq .0001)$ in preserving the syllable-final consonant. These results suggest that the types of errors speakers make is dependent on their L1. Bonferroni post-hoc tests, as shown in Table 4, indicate that there was a significant difference between L1 Japanese and both L1 Chinese $(p<.05)$ and L1 Korean $(p<.05)$ when preserving the final consonant, but not between L1 Chinese and L1 Korean. 
Table 4: Bonferroni post-hoc tests

\begin{tabular}{|l|l|l|}
\hline Dependent Variable & L1 & $p$ \\
\hline \multirow{3}{*}{ Preserve } & Japanese - Chinese & $.002^{*}$ \\
\cline { 2 - 3 } & Japanese - Korean & $.000^{*}$ \\
\cline { 2 - 3 } & Chinese - Korean & .745 \\
\hline
\end{tabular}

Next, the results from Table 3 (total number of errors from preserved syllable-final consonants) were submitted to a repeated measures ANOVA, with L1 as the between subjects variable and repair type as the within subjects variable. The results showed a significant effect for $\mathrm{L} 1(F(2,57)=12.810, p \leq .0001)$. Bonferroni post-hoc tests indicated that there was a significant difference between L1 Japanese and both L1 Chinese and L1 Korean; however, post-hoc tests once again did not confirm a significant difference between L1 Chinese and L1 Korean. There was also a significant effect for the types of repair strategies L2 learners used when they preserved the syllable-final consonant, with devoicing being used the most, followed by epenthesis, and then aspiration $(F(2,114)=24.05, p \leq .0001)$, with all comparisons being significantly different. Furthermore, a reliable L1 repair interaction $(F(2,57)=10.942, p<.05)$ was revealed between laryngeal modification (aspiration and devoicing) and epenthesis. This result means that the L1 Japanese used different strategies for dealing with syllable-final consonants compared to L1 Chinese and L1 Koreans overall.

\section{Discussion}

To address the first hypothesis, the data strongly indicates that L1 Japanese favor preserving the syllablefinal consonant, while L1 Chinese and L1 Korean speakers prefer deletion more than other repair strategies. L1 Chinese speakers deleted the final consonant more than three times as much as L1 Japanese speakers did, and more than L1 Korean speakers. In addition, it seems that L1 Japanese as a group are more consistent than the other speakers, especially L1 Chinese. Among the L1 Japanese, three speakers did not delete one single syllable-final consonant segment, and two L1 Japanese only deleted the final consonant once (a stop for one speaker, and a liquid for another). On the other hand, all Chinese speakers display evidence of deletion, but one speaker deleted more than 40 final consonant segments. Although there is more variability in the L1 Chinese data, it is the clear choice of repair strategy compared to other L1s.

However, these repair strategies are not predictable based on segment types (voiced vs. voiceless fricatives, voiced vs. voiceless stops, etc.), as the data show that multiple repair strategies are used by all L1s For example, Table 4 shows the repair strategy used by speakers in repairing the final $/ z /$ from "because," the final $/ \mathrm{v} /$ from "have," and the final /d/ from "food." The total number of production (both accurate and inaccurate production of the syllable-final consonant) of each word are in parentheses after the L1.

Table 4: Repair strategies used by L1 Japanese, L1 Chinese, and L1 Koreans

\begin{tabular}{|l|l|l|l|l|l|}
\hline Word & L1 & Epenthesis & Aspiration & Devoicing & Deletion \\
\hline \multirow{4}{*}{ Because } & Japanese (20) & 3 & 2 & 13 & 0 \\
\cline { 2 - 6 } & Chinese (22) & 0 & 0 & 17 & 2 \\
\cline { 2 - 6 } & Korean (16) & 1 & 0 & 12 & 2 \\
\hline \multirow{3}{*}{ Have } & Japanese (19) & 5 & 0 & 6 & 0 \\
\cline { 2 - 6 } & Chinese (42) & 4 & 0 & 11 & 6 \\
\cline { 2 - 6 } & Korean (28) & 9 & 0 & 4 & 1 \\
\hline \multirow{3}{*}{ Food } & Japanese (10) & 1 & 1 & 7 & 0 \\
\cline { 2 - 6 } & Chinese (17) & 4 & 1 & 3 & 2 \\
\cline { 2 - 6 } & Korean (12) & 0 & 0 & 10 & 2 \\
\hline
\end{tabular}

In production, all L1 speakers use different repair strategies within the same phonological environments. All speakers tend to devoice the final /z/ from "because," but L1 Japanese also show some evidence of epenthesis and aspiration. All speakers epenthesized the final /v/ from "have," but only L1 Chinese and L1 Koreans show evidence of deletion. In the production of "food," L1 Japanese preferred devoicing over other repair strategies (10 devoice, 1 epenthesis, 1 aspiration), and so did the L1 Koreans. However, L1 Chinese 
use many repair strategies for the final voiced stop /d/. The data show all speakers use a variety of repair strategies for even a single word, and therefore, production is not predictable by segment type.

What is it to be made of these results then between deletions and preserved syllable-final consonants, and why do L1 Japanese speakers as a whole prefer not to delete the final consonant as frequently as the other two L1s? This can be jointly addressed with the second and third hypotheses. Recall the discussion on the strategies that speakers use in segmenting syllables from section 4. In terms of the maximal syllable projection of the respective languages, syllables can end with a vowel, nasal, or a retroflex approximant in Chinese, and a vowel or unreleased consonant in Korean. Although the syllable can end with a vowel, geminate, or nasal in Japanese, the moraic structure of Japanese influences speakers to further segment the maximal syllable projection of /CGV-Q-N/ into smaller mora-sized units influenced by their L1 phonotactics. The prominence of the mora and CV structure may directly influence how L1 Japanese segment syllables with a vowel coda instead of a consonant coda. With the application of the sonority cycle and the maximal syllable projection, we suggest the following tendencies of how L1 Japanese repair syllable-final consonants: when a consonant appears in the coda position, L1 Japanese are not only inclined to preserve the final consonant, but also transfer it from the coda position to the onset position of a new mora unit. For example, Figure 2 illustrates how we predict an L1 Japanese may segment the syllable-final segments of the word "found."

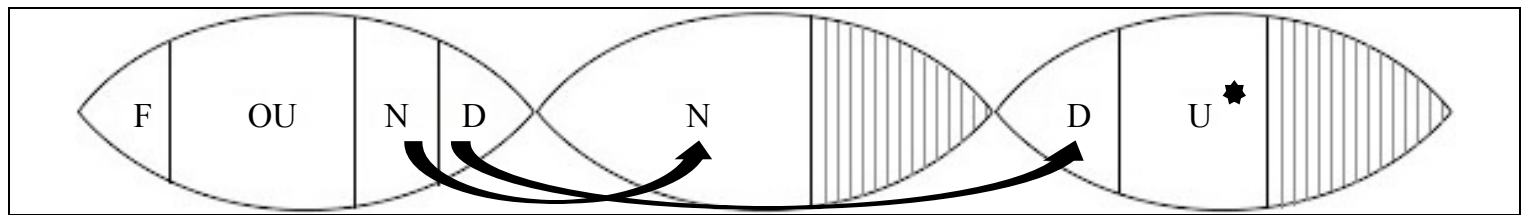

Figure 2: Segmentation strategy of "found" by L1 Japanese with epenthetic [u*]

Notice that one of the tendencies of the Japanese speaker is to move not only the [n] but also the [d] to a new mora unit as well. Since the [n] can occupy an entire mora unit in Japanese, the speaker does not need to modify the [n] anymore; however, the [d] cannot be within the same mora boundary as [n] as this would violate Japanese phonotactics. The speaker then would further establish a new mora and in the process of doing so, epenthesize the final consonant [d], as consonants cannot stand alone in Japanese. The following Figure (3) shows exactly how one of the speakers produced this word during an RSA:

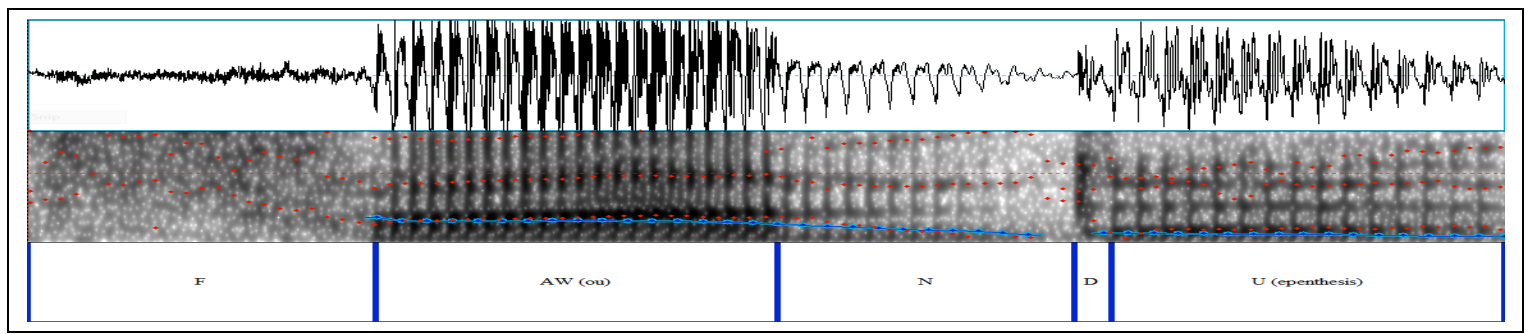

Figure 3: Production of the word "found" by an L1 Japanese speaker

Although the onset /f/ was elongated, the initial vowel produced as an /aw/ sound was 0.160 seconds in length, with the following nasal being 0.118 seconds, only a difference of 0.052 seconds. The epenthetic $/ \mathrm{u} / \mathrm{measured}$ at 0.157 seconds, with a difference of less than 0.050 seconds from the adjacent nasal $/ \mathrm{n} /$. This gives us a 1:0.74:0.98 ratio between the three morae, and is a textbook example of how the moraic structure transfers between the L1 and L2. Not only is the nasal given its own moraic unit, but the coda /d/ is epenthesized by a vowel that seems to fulfill an entire moraic unit of length. This suggests that this particular speaker has not acquired the properties of the target language syllable structure, and is still reliant on his L1 moraic structure of Japanese.

However, there is variability even within the L1 Japanese group. One L1 Japanese speaker correctly produced the diphthong /ou/, which measured at 0.317 seconds, the nasal $/ \mathrm{n} /$ at 0.128 seconds, and the epenthetic vowel $/ \mathrm{u} /$ at 0.051 seconds, giving us a 1:0.40:0.16 ratio. This indicates that this speaker has partially acquired the properties of the L2 syllable structure, but still segments each syllable based on the 
moraic structure. In addition the epenthesis produced by this speaker still resembles an /u/ sound rather than a schwa, which is another indication of the L1 phonology transferring in epenthesis. Finally, there was also an L1 Japanese speaker who did not epenthesize the final /d/, but devoiced the final consonant in production, showing evidence of preservation. In the case for L1 Chinese and L1 Koreans, once the syllable has been fulfilled, as mentioned earlier, they are not inclined to preserve segments that requires the formation of additional syllable to accommodate for the consonant codas, which is different from the case of the L1 Japanese speakers who are inclined to do so. Instead, the consonants in syllable-final positions are essentially left out, and unless the L2 learner has obtained an understanding of the L2 syllable structure, these consonants are likely to be deleted, as the results show. This evidence suggests that the L1 syllable structures, and not higher prosodic units, are playing a significant role for L1 Chinese and L1 Koreans in preserving or deleting the syllable-final consonant.

Finally, let us examine the results between the preserved syllable-final consonants. The results indicate that there is a reliable interaction between the $\mathrm{L} 1$ and repair strategies based on the types of errors they make. It is clear that L1 Japanese speakers not only prefer devoicing the syllable-final consonant, but also utilize a laryngeal modification of the final consonant, as they aspirate at a much higher rate compared to L1 Chinese and L1 Koreans. This seems to be a direct linguistic influence from the moraic structure and allophonic variation in the L1. One reason why L1 Japanese devoice more than L1 Chinese and L1 Koreans may lie in the fact that devoicing is a part of Japanese phonology and allophonic processes. As noted earlier, vowel devoicing is fairly common in Japanese, especially for high vowels that appear between two voiceless segments, such [kita] (lit. 'north' or 'came'). Thus, it seems that L1 Japanese speakers have access to devoicing as a repair strategy, as it is already a part of their L1 phonology. Such allophony is related to Japanese being a pitch-accent language, in which the low pitch segment that is unaccented can be devoiced, if it occurs between two voiceless segments (Tsuchida, 2001; Vance, 1987). However, Chinese and Koreans do not have access to devoicing, because it is not part of their L1 phonology. In Chinese, devoicing vowels would make it impossible to utilize tone, and devoicing is not available in Korean as all syllables must include a vowel segment.

As laryngeal modification is available in Japanese, subsequently L1 Japanese aspirated at a much higher rate than the other two L1 groups is. The question arises as to why L1 Chinese and L1 Koreans delete at a fairly high rate as well if they do not have access to this modification strategy. One explanation may be the fact that voiced consonants, especially in the coda position, are difficult for many L2 learners to accurately articulate and produce, particularly for L1 speakers whose native language restricts syllable-final consonants. The mechanism required to sustain voicing of an obstruent for a short duration of time is difficult for L1 Japanese, L1 Chinese, and L1 Koreans when a vowel does not appear after the obstruent. Second, the cues in voicing changes in English for when obstruents are in coda positions may not be as available for the L2 learner as they are for native English speakers. The main cue for voicing syllable-final obstruents in English is based on the ratio between the preceding vowel and the coda consonant. Vowels that are inherently short will lead to the following consonant being devoiced, and subsequently, vowels that are inherently long will cue native English speakers to voice the final consonant, such as in 'build-built' and 'rabid-rapid' (Port \& Leary, 2000). In the data, however, we find many examples where even though the vowel is inherently long in the word, such as in "because," speakers tend to devoice the final /z/. This implies that the L2 learner has not fully acquired the cues in voicing changes in English. Furthermore, the inability to employ such cues may also be restricted by the $\mathrm{VC}$ structure of voicing cues, a phonotactic structure that is foreign to Japanese, Chinese, or Korean. Therefore, linguistic, phonological, and syllable structures all jointly play a significant role over L1-L2 transfer in all three languages.

\section{Conclusion}

This study investigated the influence of moraic structure in L2 production of syllable-final consonants among L1 Japanese speakers, in comparison with Chinese and Korean that have similar syllable structures. We found that moraic structure does play a significant role for L1 Japanese, and syllable structures of Chinese and Korean also affect their production in L2 English. Thus, L2 data provides evidence for the existence of a prosodic unit in Japanese that has been questioned and shows how L2 data can shed light on theoretical problems in $\mathrm{L} 1$. 
Limitations of this study include the fact that much learner and language variability in phonological acquisition exists, as well as other factors. One such factor is the prevalence of loanwords in each of the L1s, to which no doubt every speaker has been exposed to in their native language. In Japanese alone, there are over 40,000 loanwords in the language system, over 90\% of which are English, and new loanwords are consistently being imported. As the use of loanwords are regularized as native Japanese words, L1 Japanese speakers are constantly being exposed to English words that are essentially "Japanized" when they are borrowed. This likely creates phonological categories of English loanwords with Japanese pronunciation that are difficult to overcome when learning English. Such was the case for words such as "topic," "big," or the first part of "apartment," which all showed signs of loanword transfer in the data (these words were excluded from the analysis). Although spontaneous speech is widely agreed upon to be the best form of speech to analyze, we leave the possibility of conducting similar studies with a word-list that does not consist of loanwords for the future.

The data presented suggest a cross-linguistic analysis of the duration of epenthesized syllable-final consonants is appropriate for future research. Preliminary evidence indicates L1 Japanese speakers tend to produce an approximate 1:1 ratio between the duration of the preceding and epenthesized vowels. If evidence shows that L1 Chinese and L1 Koreans do not exhibit an approximate 1:1 durational ratio, we are able to make a stronger case of the transfer of the moraic structure among L1 Japanese speakers learning L2 English. In order to make such a claim, further investigation should include durational comparisons of epenthetic vowels found in the same word, such as "found," or any other word that all three L1 groups produced during the task. Finally, this study only included intermediate level speakers, and focused on the production of syllable-final consonants. As we have established the significance of the moraic structure in L1-L2 transfer for Japanese, further research could explore examining other levels in L2 learners, for example, L1 Japanese with zero exposure to the target language and learners who may be said to have completed acquisition.

\section{References}

Abrahamsson, Niclas (2003). Development and recoverability of L2 codas. Studies in Second Language Acquisition, 25, 313-349. doi: 10.1017.S0272263103000147

Ahn, Sang-Cheol (1998). An introduction to Korean phonology. Seoul, KR: Hanshin Publishing.

Aoyama, Katsura, James Emil Flege, Susan G. Guion, Reiko Akahane-Yamada \& Tsuneo Yamada (2004). Perceived phonetic dissimilarity and L2 speech learning: the case of Japanese /r/ and English /1/ and /r/. Journal of Phonetics, 32, 233-250. doi: 10.1016/S0095-4470(03)00036-6

Best, Catherine T. (1995). A direct realist view of cross-language speech perception. In W. Strange (Ed.), Speech perception and linguistic experience: Issues in cross-language research (pp. 171-204). Timonium, MD: York Press.

Bradlow, Ann, Robert F. Port \& Keiichi Tajima (1995). The combined effects of prosodic variation on Japanese mora timing. Proceedings of the $13^{\text {th }}$ International Congress of Phonetic Sciences, 1, 198-201. Stockholm, SE.

Broselow, Ellen \& Daniel Finer (1991). Parameter setting in second language phonology and syntax. Second Language Research, 7, 35-59. doi: 10.1177/026765839100700102

Broselow, Ellen, Su-I Chen \& Chilin Wang (1998). The emergence of the unmarked in second language phonology. Studies in Second Language Acquisition, 20, 261-280.

Brown, Cynthia (2000). The interrelation between speech perception and phonological acquisition from infant to adult. In J. Archibald (Ed.), Second language acquisition and linguistic theory (pp. 4-63). Malden, MA: Blackwell Publishers Inc.

Chan, Alice Y.W. (2008). Cantonese ESL learners' pronunciation of English final consonants. Language, Culture and Curriculum, 19, 296-313. doi: 10.1080/07908310608668769

Clements, George N. (1990). The role of the sonority cycle in core syllabification. In J. Kingston \& M. Beckman (Eds.), Papers in laboratory Phonology I (pp. 283-333). Cambridge, UK: Cambridge University Press.

Cutler, Anne \& Takashi Otake (1994). Mora or phoneme? Further evidence for language-specific listening. Journal of Memory and Language, 33, 824-844. doi: 10.1006/jmla.1994.1039

Dauer, Rebecca M. (1987). Phonetic and phonological components of language rhythm. Proceedings of the $11^{\text {th }}$ International Congress of Phonetic Sciences, 5, 447-450. Talinn, EE.

Duanmu, San (1990). A formal study of syllable, tone, stress, and domain in Chinese. Doctoral dissertation, MIT, Cambridge, MA.

Dupoux, Emmanuel, Kazuhiko Kakehi, Yuki Hirose, Christophe Pallier \& Jacques Mehler (1999). Epenthetic vowels in Japanese: A perceptual illusion? Journal of experimental psychology: Human perception and performance, 25, 1568-1578. doi: 10.1037/0096-1523.25.6.1568

Eckman, Fred \& Gregory Iverson (1994). Pronunciation difficulties in ESL: Coda consonants in English interlanguage. In M. Yavas (Ed.), First and second language phonology (pp. 251-266). San Diego, CA: Singular Publishing Group. 
Edge, Beverly A. (1991). The production of word-final voiced obstruents in English by speakers of Japanese and Cantonese. Studies in Second Language Acquisition, 13, 377-393.

Flege, James Emil (1995) Second language speech learning theory, findings, and problems. In W. Strange (Ed.), Speech perception and linguistic experience: Issues in cross-language research (pp. 233-277). Timonium, MD: York Press.

Hancin-Bhatt, Barbara, \& Rakesh M. Bhatt (1997). Optimal L2 syllables. Studies in Second Language Acquisition, 19, 331-378.

Hansen, Jette G. (2001). Linguistic constraints on the acquisition of English syllable codas by native speakers of Mandarin Chinese. Applied Linguistics, 22, 338-365.

Hansen, Jette G. (2004). Developmental sequences in the acquisition of English L2 syllable codas. Studies in Second Language Acquisition, 26, 85-124. doi: 10.1017/S0272263104261046

Kabak, Baris \& William J. Idsardi (2007). Perceptual distortions in the adaptation of English consonant clusters: syllable structure or consonantal contact constraints? Language and Speech, 50, 23-52.

Kang, Yoojung (2003). Perceptual similarity in loanword adaptation: Adaptation of English post-vocalic word-final stops to Korean. Phonology 20, 219-273.

Kubozono, Haruo (1995). Perceptual evidence for the mora in Japanese. In B. Connel \& A. Arvaniti (Eds.), Phonology and Phonetic Evidence: Papers in Laboratory Phonology IV (pp. 141-156). Cambridge, UK: Cambridge University Press.

Kubozono, Haruo (2002). Mora and Syllable. In N. Tsujimura (Ed.), The handbook of Japanese linguistics (pp. 31-61). Malden, MA: Blackwell Publishers Inc.

Labrune, Laurence (2012). Questioning the universality of the syllable: evidence from Japanese. Phonology, 29, 113152. doi: $10.1017 / \mathrm{S} 095267571200005 \mathrm{X}$

Lado, Robert (1957). Linguistics across cultures. Ann Arbor: University of Michigan Press.

Masuda, Hinako \& Takayuki Arai (2010). Processing of consonant clusters by Japanese native speakers: Influence of English learning backgrounds. Acoustical Science and Technology, 31, 320-327.

Murty, Lalita, Takashi Otake \& Anne Cutler. (2007). Perceptual tests of rhythmic similarity: I. mora rhythm. Language and Speech, 50, 77-99.

Nogita, Akitsugu (2011). Epenthesis, intrusion, or deletion? Vowel alternation in consonant clusters by Japanese ESL learners. In Working Papers of the Linguistic Circle of the University of Victoria, Volume 21, pp. 43-51, Victoria, $\mathrm{BC}$.

Otake, Takashi, Giyoo Hatano, Anne Cutler \& Jacques Mehler (1993). Mora or syllable? Speech segmentation in Japanese. Journal of Memory and Language, 32, 258-278. doi: 10.1006/jmla.1993.1014

Port, Robert F. \& Adam P. Leary (2000). Speech timing and linguistic theory. Department of Linguistics, Indiana University. Manuscript.

Port, Robert F., Jonathan Dalby \& Michael O'Dell (1987). Evidence for mora timing in Japanese. Journal of Acoustical Society of America, 81, 1574-1585. doi: 10.1121/1.394510

Port, Robert F., Salman Al-Ani \& Shosaku Maeda (1980). Temporal compensation and universal phonetics. Phonetica, 37 235-252.

Selkirk, Elizabeth O. (1984). On the major class features and syllable theory. In M. Arnolf \& R. T. Octyle (Eds.), Language and sound structure (pp. 107-136). Cambridge, MA: MIT Press.

Shibatani, Masayoshi (1990). The languages of Japan. Cambridge, UK: Cambridge University Press.

Tajima, Keiichi, Donna Erickson \& Kyoko Nagao (2003). Production of syllable structure in a second language: Factors affecting vowel epenthesis in Japanese-accented English. In Speech Prosody and Timing: Dynamic Aspects of Speech (Indiana University Working Papers in Linguistics, Volume 4), pp. 77-92, Bloomington, IN.

Tsuchida, Ayako (2001). Japanese vowel devoicing: Case of consecutive devoicing environments. Journal of East Asian Linguistics, 10, 225-245.

Tsujimura, Natsuko (2007). An introduction to Japanese linguistics. Malden, MA: Blackwell Publishing.

Trofimovich, Pavel \& Wendy Baker (2006). Learning second language suprasegmentals: Effect of L2 experience on prosody and fluency characteristics of L2 speech. Studies in Second Language Acquisition, 28, 1-30. doi: $10.1017 / \mathrm{S} 0272263106060013$

Vance, Timothy J. (1987). An introduction to Japanese phonology. Albany, NY: State University of New York Press.

Wang, Chilin (1995). The acquisition of English word-final obstruents by Chinese speakers. Doctoral dissertation, State University of New York at Stony Brook, NY.

Warner, Natasha \& Takayuki Arai (2001). Japanese mora-timing: A review. Phonetica, 58, 1-25.

Young-Scholten, Martha \& John Archibald (2000). Second language syllable structure. In J. Archibald (Ed.), Second language acquisition and linguistic theory (pp. 4-63). Malden, MA: Blackwell Publishers Inc. 